\title{
Synthesis of silver nanoparticles using seed exudates of Sinapis arvensis as a novel bioresource, and evaluation of their antifungal activity
}

\author{
Mehrdad Khatami ${ }^{1,2^{*}}$, Shahram Pourseyedi ${ }^{1}$, Mansour Khatami ${ }^{2}$, Hadi Hamidi ${ }^{1}$, Mehrnaz Zaeifi ${ }^{3}$ and Lida Soltani ${ }^{3}$
}

\begin{abstract}
Background: In general, silver nanoparticles (AgNPs) are particles of silver with a size less than $100 \mathrm{~nm}$. In recent years, synthesis of nanoparticles using plant extract has gained much interest in nanobiotechnology. In this concern, this study investigates green synthesis of AgNPs from silver nitrate using Sinapis arvensis as a novel bioresource of cost-effective nonhazardous reducing and stabilizing compounds. A stock solution of silver nitrate (0.1 M) was prepared. Different concentrations of silver nitrate $(1,2.5,4$, and $5 \mathrm{mM})$ were prepared from the above solution, then added to $5 \mathrm{~mL}$ of $\mathrm{S}$. arvensis seed exudates. The mixtures were kept in $25^{\circ} \mathrm{C}$. The synthesis of AgNPs was confirmed by the change in mixtures color from light yellow to brown. The antifungal activity of synthesized AgNPs was investigated in vitro.

Results: The resulting AgNPs were characterized by UV-vis spectroscopy, X-ray diffraction (XRD), transmission electron microscopy (TEM), and Fourier transform infrared spectroscopy (FTIR). Formation of the AgNPs was confirmed by the change in mixture color from light yellow to brown and maximum absorption at $412 \mathrm{~nm}$ due to surface plasmon resonance of AgNPs. The role of different functional groups in the formation of AgNPs was shown by FTIR. X-ray diffraction was shown that the AgNPs formed in our experiments were in the form of nanocrystal, and TEM analysis showed spherical particles with an average size of $14 \mathrm{~nm}$. Our measurements indicated that $\mathrm{S}$. arvensis seed exudates can mediate facile and eco-friendly biosynthesis of colloidal-spherical AgNPs with a size range of 1 to $35 \mathrm{~nm}$. The synthesized AgNPs showed significance antifungal activity against Neofusicoccum parvum cultures.

Conclusion: The AgNPs were synthesized using a biological source. This synthesis method is nontoxic, eco-friendly, and a low-cost technology for the large-scale production. The AgNPs can be used as a new generation of antifungal agents.
\end{abstract}

Keywords: Synthesis; AgNPs; Spherical AgNPs; Antifungal

\section{Background}

Silver nanoparticles (AgNPs) are particles of silver which are in the range between 1 and $100 \mathrm{~nm}$. Nanostructure materials indicate unique physicochemical and biological environmental properties, including optical, magnetic, electronic, catalytic activity, and biological properties [1], which have increased their applications in medicine, agriculture, environment, and industry [2]. AgNPs have

\footnotetext{
* Correspondence: mehrdad7khatami@gmail.com

'Department of Biotechnology, Shahid Bahonar University of Kerman, End of 22-Bahman Blvd, 76169-133, Kerman 76189-18951, Iran

${ }^{2}$ Department of Enviroment, The Enviromental Researches Center, Havaniroz Street, Jomhori Blvd, Kerman 76189-18951, Iran

Full list of author information is available at the end of the article
}

high potential as commercial nanomaterials [3] and an effective antimicrobial agent.

Several techniques for synthesizing AgNPs have been proposed. Generally, AgNPs are prepared by different kinds of chemical and physical methods, but majority of these techniques are both expensive and environmentally hazardous [4]. Furthermore, the synthesized nanoparticles may be unstable and tend to agglomerate rapidly and become useless unless capping agents are applied for their stabilization [5]. Diverse chemical and physical methods have been used to prepare AgNPs with various sizes and shapes, such as UV irradiation [6,7], microware irradiation [8], chemical reduction [9], 
electron irradiation [10], photochemical [11], and lithography methods [12]. However, most of these methods involve more than one step, high energy requirement, low material conversions, difficulty in purification, and hazardous chemicals [13]. The synthesis of nanoparticles by chemical methods may lead to the production of some toxic chemical compound that may have adverse effects on their applications [14].

The biological synthesis of nanoparticles can potentially eliminate these problems. Biological synthesis of nanoparticles is nontoxic, eco-friendly, and a low-cost technology for the large-scale production of well-characterized nanoparticles [14]. Therefore, there is a need to develop biological processes for nanoparticle synthesis. Recently, many live organisms such as bacteria, fungi, algae, and plants have been used for synthesis of nanoparticles [15-17]. The reduction of $\mathrm{Ag}^{+}$to $\mathrm{Ag}^{0}$ took place by combinations of biomolecules such as proteins, polysaccharides, and flavonoids [18]. Green synthesis of AgNPs has become very important in the recent years. Green AgNPs have the potential for large scale applications in the formulation of dental resin composites, bone cement $[19,20]$, water and air filters [21,22], clothing and textiles, medical devices and implants [23], cosmetics [4], and packaging [24]. Besides their antimicrobial properties, AgNPs and silver nanocomposites have other interesting characteristics which will further enable them to be used in catalysts, biosensors, conductive inks, and electronic devices $[25,26]$. They can be produced economically and in large industrial scale [14].

In this paper, we report biosynthesis of stable colloidal AgNPs using Sinapis arvensis seed exudates. This plant is an important medicinal crop in the southern regions of Iran. Antifungal activities of synthesized AgNPs were also investigated. Details of biosynthesis, physical characterizations, and antifungal activity of AgNPs are described.

\section{Methods}

Reagents

Silver nitrate and potato dextrose agar (PDA) medium were obtained from Merck, Darmstadt, Germany. Seeds of $S$. arvensis were obtained from Pakanbazr, Isfahan, Iran. Strain of the fungus N. parvum was prepared from the Department of Plant Protection, Shahid Bahonar University of Kerman, Iran.

\section{Seed exudates preparation}

The surface of $S$. arvensis seeds were disinfected using $30 \%$ sodium hypochlorite for 5 min and rinsed with sterile distilled water three times. In the next step, the seeds were placed in $70 \%$ alcohol for $2 \mathrm{~min}$ and then washed four times with sterile distilled water and then imbibed in deionized (DI) water. (1 $\mathrm{g}$ dry weight/10 $\mathrm{mL}$ DI water)
After being incubated at $25^{\circ} \mathrm{C}$ for $48 \mathrm{~h}$ in the dark, seeds were removed from the soaking medium. The supernatant phase was collected and centrifuged at 4,500 rpm for $10 \mathrm{~min}$ to separate the liquid fraction from any large insoluble particles and filtered by Whatman filter paper no. 1 (Sigma Aldrich, St. Louis, MO, USA). During the experiment, $\mathrm{pH}$ was 4.5 .

\section{Biosynthesis of AgNPs}

For this reason, a $50 \mathrm{~mL}$ stock solution containing $0.1 \mathrm{M}$ silver nitrate was prepared. Different concentrations of silver nitrate $(1,2.5,4$, and $5 \mathrm{mM})$ were prepared from the above solution, then added to $5 \mathrm{~mL}$ of $S$. arvensis seed exudates and incubated at $25^{\circ} \mathrm{C}$ as described previously [27]. After treatment, the pale yellow color of reaction mixture was changed to brown indicating synthesis of AgNPs.

\section{Characterization of AgNPs \\ UV-vis spectroscopy}

The biosynthesis of AgNPs was monitored periodically using a UV-vis spectrophotometer (Scan Drop-type product, Analytik Jena, Germany) at different concentrations at room temperature. These measurements operated at a resolution of $1 \mathrm{~nm}$ and wavelength range between 300 and $650 \mathrm{~nm}$ [14].

\section{$X$-ray diffraction}

The formation and quality of compounds were investigated by X-ray diffraction (XRD) technique. For this purpose, AgNPs was centrifuged (at $13,000 \mathrm{rpm} ; 25^{\circ} \mathrm{C}$ ) for $10 \mathrm{~min}$, washed with DI water and re-centrifuged in three cycles. Then purified AgNPs were dried and subjected to XRD experiment. X-ray diffraction was performed by STOE Stadi P (STOE \& Cie. GmbH, Darmstadt, Germany) ( $\lambda=1.54178 \AA$ ). The scanning was done in the region of $2 \theta$ from $10^{\circ}$ to $80^{\circ}$ [17].

\section{Transmission electron microscopy}

Transmission electron microscopy (TEM) was performed by using of a Carl Zeiss (Jena, Germany, $80 \mathrm{kV}$ ) for determining the morphology and size of AgNPs.

\section{Inductively coupled plasma spectrometry}

Inductively coupled plasma spectrometry (ICP) Varian BV ES-700, Sydney, Australia, was used to determining the remaining concentration of silver ions after synthesizing AgNPs. Changing rate of metal ion to nanoparticles is calculated by the following equation:

$$
Q=\left(\frac{C_{0}-C_{f}}{C_{0}}\right) \times 100
$$

where $\mathrm{C}_{0}$ and $\mathrm{C}_{\mathrm{f}}$ stands for initial and final concentration 


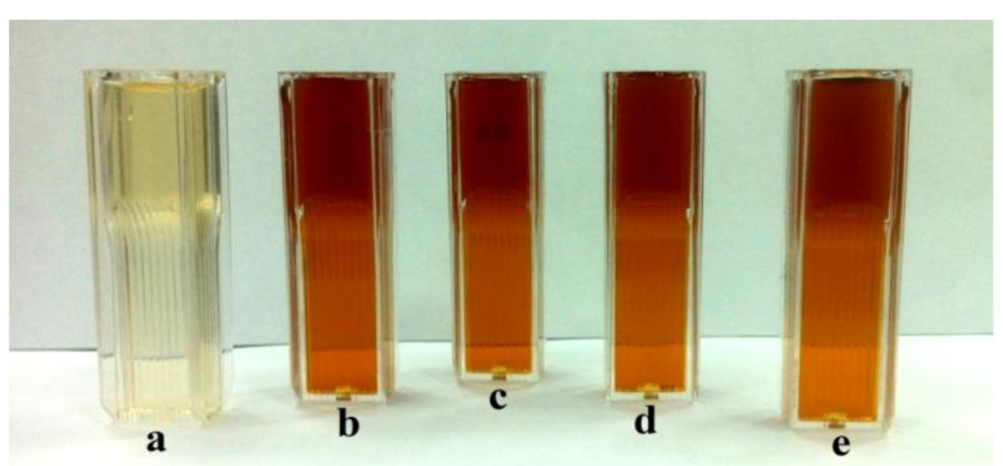

Figure $\mathbf{1}$ Reduction of $\mathbf{A g}^{+}$to $\mathbf{A g}^{\mathbf{0}}$. The color change of the S. arvensis exudates upon the formation of AgNPs from different concentrations of silver nitrate: (a) control, (b) $1 \mathrm{mM}$, (c) $2.5 \mathrm{mM}$, (d) $4 \mathrm{mM}$, and (e) $5 \mathrm{mM}$.

of silver ion $(\mathrm{mg} / \mathrm{L})$, respectively. $Q$ is the conversion percentage of silver ion to AgNPs [28].

\section{Antifungal activity of AgNPs}

To determine the antifungal activity of AgNPs, mycelium growth inhibition test was used. Four concentrations of AgNPs $(2.5,5,10$, and $40 \mu \mathrm{g} / \mathrm{mL})$ were prepared in PDA medium after autoclaving. 6-mm agar plugs of fresh culture of $N$. parvum prepared and transferred to centers of media containing different concentrations of synthesized AgNPs. Control plates contain no AgNPs. All plates incubated at $28^{\circ} \mathrm{C}$. When in control, the fungus completely covered the entire surface of the medium, the mean radius of fungal growth in all plates measured and recorded [29]. All treatments were performed in triplicates.
The following formula was used to assess of the growth inhibition of mycelium:

$$
\text { Mycelium growth inhibition } \%=\frac{R-r}{R} \times 100
$$

$R$ is the mean radius of control and $r$ is the radius of samples treated with nanoparticle. Data processed with SAS statistical analysis using Duncan's test.

\section{Results and discussion}

\section{Visual observation}

Reduction of $\mathrm{Ag}^{+}$to $\mathrm{Ag}^{0}$ was confirmed by color change of the reaction mixture from colorless to brown (Figure 1).

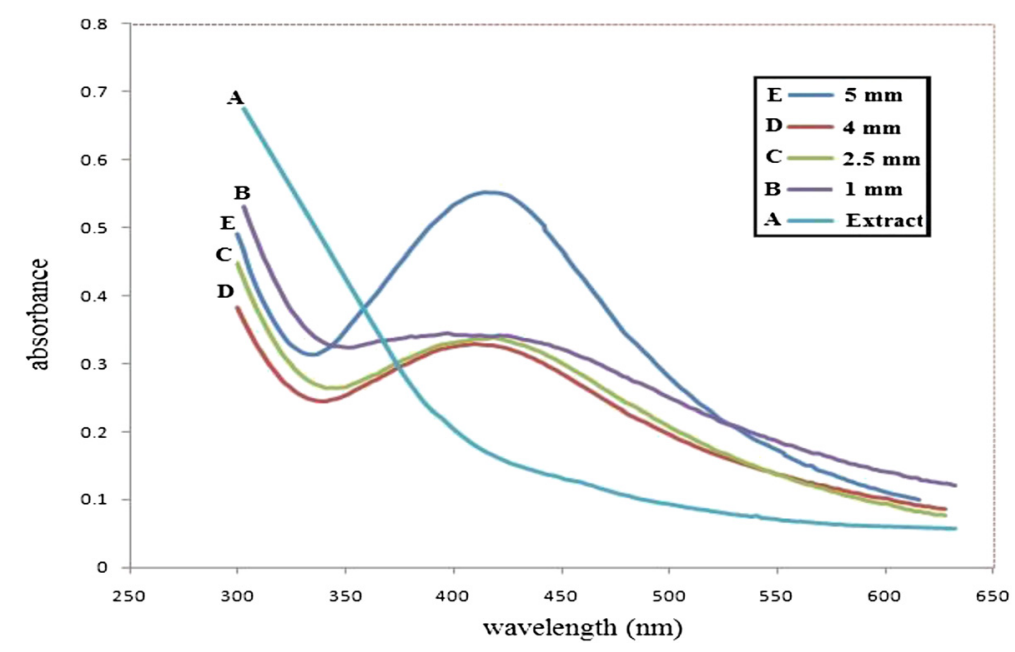

Figure 2 UV-vis absorption spectrum of AgNPs synthesized by treating 1, 2.5, 4, and $5 \mathrm{mM}$ silver nanoparticles after 1 week. 


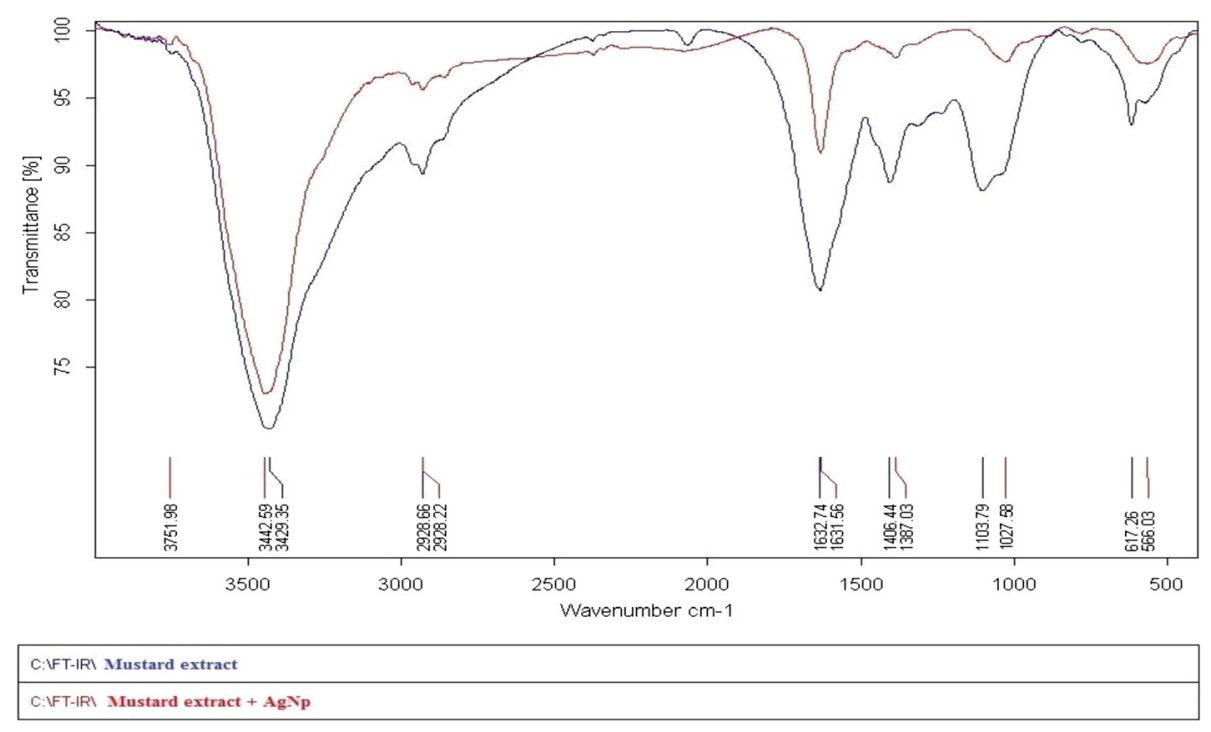

Figure 3 FTIR spectra of the S. arvensis exudates before and after the synthesis of AgNPs.

\section{Ultraviolet visible scanning spectroscopy studies}

It was observed that the maximum absorbance of reaction mixture occurs at $412 \mathrm{~nm}$, indicating that AgNPs were produced. Figure 2 shows the UV-vis absorption spectra of synthesized AgNPs with different concentrations of silver nitrate.

\section{FTIR analysis}

Fourier transform infrared spectroscopy (FTIR) spectrum of biosynthesized AgNPs shows absorption peaks at 3,429, $2,928,1,632,1,406,1,103$, and $617 \mathrm{~cm}^{-1}$ (Figure 3). Strong absorption peak at $3,429 \mathrm{~cm}^{-1}$ is resulted from stretching of the N-H band of amino groups or is indicative of present $\mathrm{O}-\mathrm{H}$ groups due to the presence of alcohols, phenols, carbohydrates, etc. The peak that appeared around $2,928 \mathrm{~cm}^{-1}$ is related to the stretching of the $\mathrm{C}-\mathrm{H}$ bonds [30]. The peaks at 1,632 and 1,406 $\mathrm{cm}^{-1}$ are assigned for aliphatic amines. The absorption peak at $1,632 \mathrm{~cm}^{-1}$ is close to that reported for native proteins [31]. The peak at $1,406 \mathrm{~cm}^{-1}$ corresponds to $\mathrm{C}-\mathrm{C}$ stretching vibrations for aromatic ring [32]. FTIR study indicates that probably the carboxyl $(-\mathrm{C}=\mathrm{O})$, hydroxyl $(-\mathrm{OH})$, and amine $(\mathrm{N}-\mathrm{H})$ groups in seed exudates are mainly involved in the reduction of $\mathrm{Ag}^{+}$ions to $\mathrm{Ag}^{0}$ nanoparticles.

\section{XRD analysis}

The formation of the nanocrystalline AgNPs was further confirmed by the XRD analysis as showed in Figure 4.

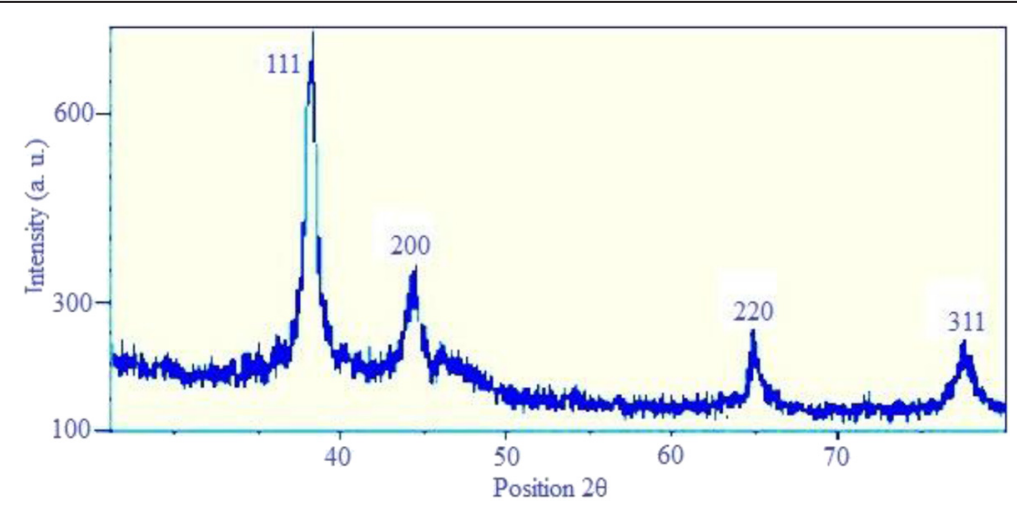

Figure 4 XRD pattern of AgNPs synthesized by treating silver nitrate with S. arvensis seed exudates. 

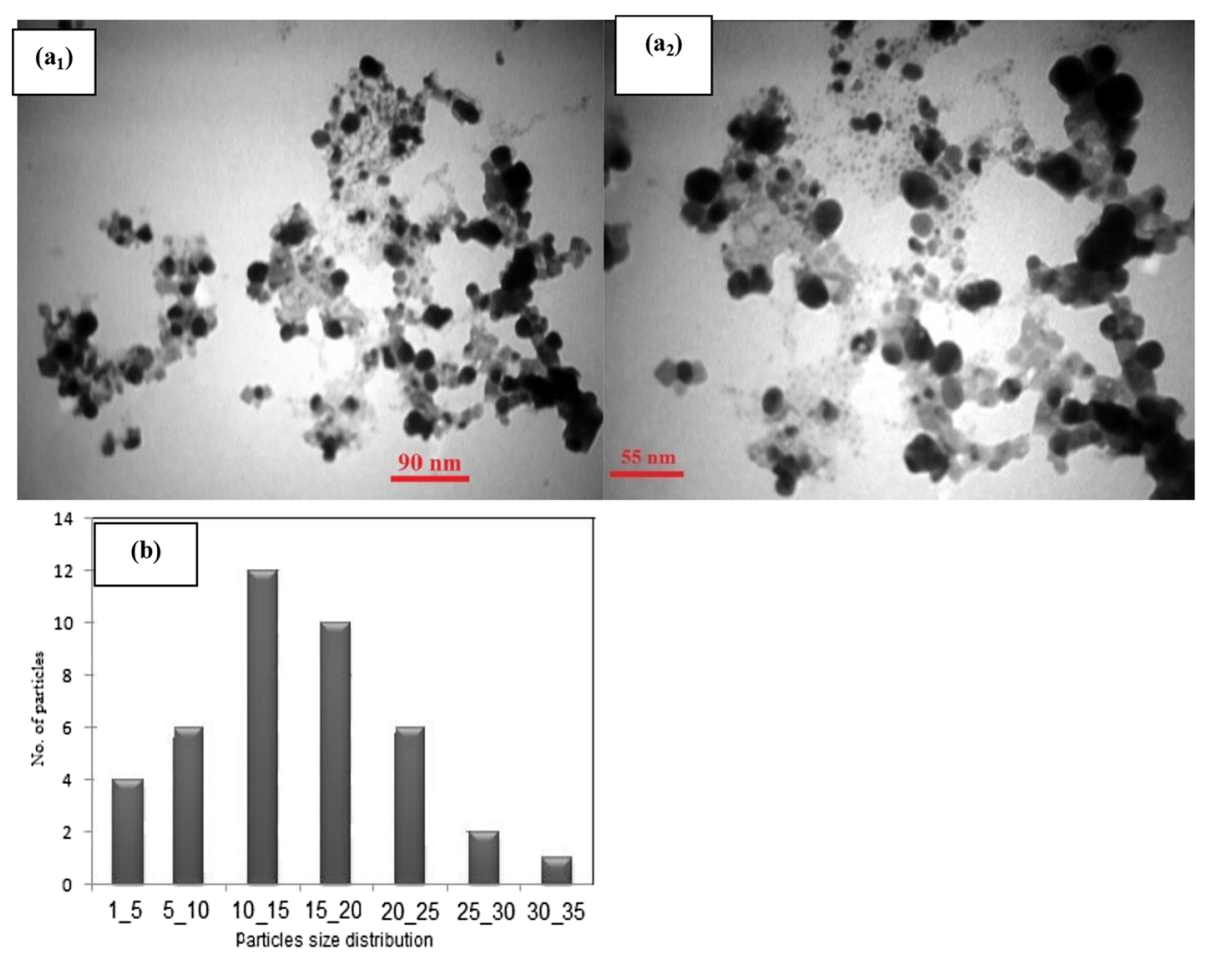

Figure $\mathbf{5}$ The TEM images of the prepared AgNPs. $\left(\mathbf{a}_{1}, \mathbf{a}_{2}\right)$ TEM images of AgNPs that were synthesized by S. arvensis seed exudates in different scales. (b) Histogram of particle size distribution of the biosynthesized AgNPs.

Strong peaks were observed at $2 \theta$ values at $38.09^{\circ}$, $44.15^{\circ}, 64.67^{\circ}$, and $77.54^{\circ}$, corresponding to (111), (200), (220), and (311) Bragg's reflection based on the facecentered-cubic (fcc) crystal structure of AgNPs [33]. The broadening of Bragg's peaks indicates the formation of AgNPs. The XRD pattern thus shows that the AgNPs formed by the reduction of $\mathrm{Ag}^{+}$ions by $\mathrm{S}$. arvensis seed exudates are crystalline in nature.

\section{Transmission electron microscopy analysis}

TEM was used to determine the size and shape of nanoparticles. The TEM images of the prepared AgNPs at 55 and $90 \mathrm{~nm}$ scales are shown in the Figure $5 \mathrm{a}_{1}$ and $a_{2}$. TEM images show that they have spherical shape. Particle size distribution histogram determined from TEM is shown in Figure 5b. AgNPs size is between 1 and $35 \mathrm{~nm}$.

Table 1 ICP analysis

\begin{tabular}{lcc}
\hline $\mathrm{Q}(\%)$ & $C_{\boldsymbol{f}}(\boldsymbol{\mu g} / \mathrm{mL})$ & $C_{0}(\boldsymbol{\mu g} / \mathrm{mL})$ \\
\hline 0.955 & 23.85 & 535 \\
\hline
\end{tabular}

\section{Inductively coupled plasma spectrometry}

ICP analysis revealed complete reduction of Ag ions within 50 days of the reaction, and more importantly, it showed that the conversion percentage of metal ion to metal nanoparticles is more than $95 \%$ (Table 1).

\section{Antifungal activity of synthesized AgNPs}

Inhibitory effects on fungal growth in a PDA medium containing $2.5,5,10$, and $40 \mu \mathrm{g} / \mathrm{mL}$ concentrations of AgNPs were studied. The results showed a very significant effect of synthesized AgNPs on the mycelium growth of the fungus $N$. parvum. More than $83 \%$ mycelium growth inhibition of the fungus $N$. parvum was treated with a concentration of $40 \mu \mathrm{g} / \mathrm{mL}$ of AgNPs. The lowest level of growth inhibition was observed at a concentration of $2.5 \mu \mathrm{g} / \mathrm{mL}$ of AgNPs with the $15 \%$ mycelium growth inhibition. The growth inhibition for concentrations of 5 and $10 \mu \mathrm{g} / \mathrm{mL}$, respectively, were $15 \%$ and $71 \%$. Results clearly showed that with the increase in the concentration of AgNPs, the inhibitory effects on fungal mycelium growth increased (Figure 6).

Percentage of growth inhibition due to the effect of AgNPs was analyzed by statistical software SAS. Results confirmed a significant effect of AgNPs on fungal growth inhibition at $1 \%$ confidence interval. 


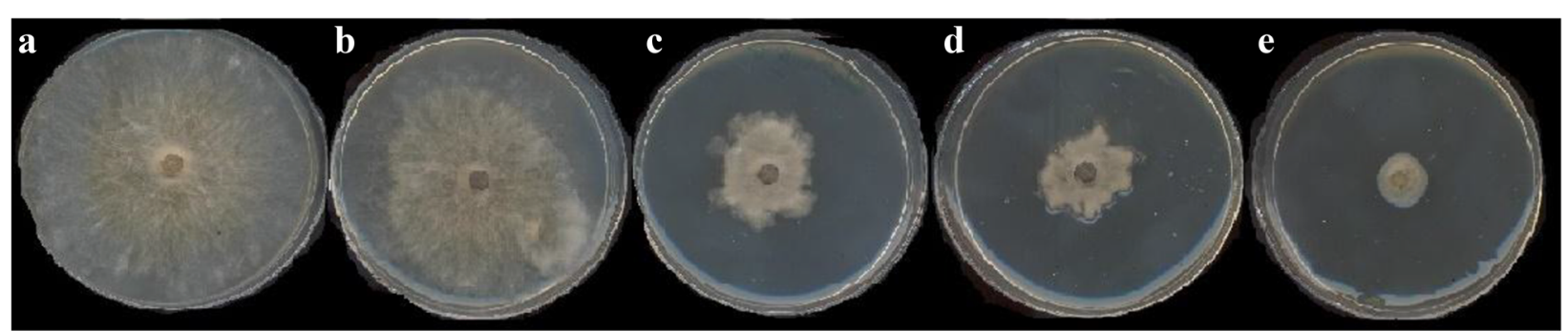

Figure 6 Inhibitory effects on fungal mycelium growth. Fungal growth on PDA medium containing control (a). PDA medium containing (b) $2.5 \mu \mathrm{g} / \mathrm{mL}$, (c) $5 \mu \mathrm{g} / \mathrm{mL}$, (d) $10 \mu \mathrm{g} / \mathrm{mL}$, and (e) $40 \mu \mathrm{g} / \mathrm{mL}$ of AgNPs.

\section{Conclusions}

Metallic nanoparticles are traditionally synthesized by wet chemical synthesis techniques where the chemicals used are quite often toxic and flammable. But in this study, the $S$. arvensis seed exudates were successfully used for the single-pot biosynthesis of spherical AgNPs in ambient conditions with the size range from 1 to $35 \mathrm{~nm}$, as inferred from the TEM imaging. This was achieved without the use of external stabilizing or capping agents. We concluded that S. arvensis seed exudates are a bioreductant and capping agent as well as an easily available plant source playing an important role in the synthesis of highly stable AgNPs. X-ray diffraction pattern strongly indicated a high purity of biosynthesized AgNPs. This pristine method is facile, cost effective, clean and green, and therefore is applicable for a variety of purposes. Moreover, it is easy to scale up the production of AgNPs to industrial scale using this method.

This green chemistry approach towards the synthesis of AgNPs has many advantages such as ease with which the process can be scaled up, economic viability, etc. Application of such nanoparticles in medicine and other applications makes this method useful for the large scale synthesis of other inorganic nanomaterials. Toxicity studies of AgNPs on pathogen open a door for a new range of antifungal and antibacterial agents. So in the present study, we demonstrated that AgNPs have significant antifungal activity. It was determined that the growth inhibitory effect of AgNPs strongly depends on the concentration of AgNPs and with the increase concentration of AgNPs in the medium the inhibitory effect on fungal growth increased. So AgNPs can be used as excellent new antifungal agent.

\section{Competing interests}

The authors declare that they have no competing interests.

\section{Authors' contributions}

All of them have been also involved in the drafting and revision of the manuscript. All authors read and approved the final manuscript.

\section{Acknowledgements}

The authors are thankful to all members of the Department of Biotechnology Science, University of Kerman. We also acknowledge Mr. Abazari, Laboratory of Science, University of Kerman, for helping us. Also, the authors are thankful to the Iran Nanotechnology Council. Dr. Jian He Xu and Dr. Zolala J have made substantive intellectual contributions to this study, substantial contributions to the conception and design of it as well as to the acquisition, analysis, and interpretation of data.

\section{Author details}

'Department of Biotechnology, Shahid Bahonar University of Kerman, End of 22-Bahman Blvd, 76169-133, Kerman 76189-18951, Iran. ²Department of Enviroment, The Enviromental Researches Center, Havaniroz Street, Jomhori Blvd, Kerman 76189-18951, Iran. ${ }^{3}$ Department of Plant Protection, Shahid Bahonar University of Kerman, End of 22-Bahman Blvd, 76169-133, Kerman 76169-14111, Iran.

Received: 18 November 2014 Accepted: 25 February 2015 Published online: 25 April 2015

\section{References}

1. Phanjom P, Ahmed G (2015) Biosynthesis of silver nanoparticles by Aspergillus oryzae (MTCC No. 1846) and its characterizations. Nanoscience and Nanotechnology 5:14-21

2. Song JY, Kim BS (2009) Rapid biological synthesis of silver nanoparticles using plant leaf extract. Bioprocess Biosyst Eng 32:79-84

3. Chaloupka K, Malam Y, Seifalian AM (2010) Nanosilver as a new generation of nanoproduct in biomedical applications. Trends Biotechnol 28:580-588

4. Sintubin L, Verstraete W, Boon N (2012) Biologically produced nanosilver: current state and future perspectives. Bioeng 109:2422-2436

5. Kassaee M, Akhavan A, Sheikh N, Sodagar A (2008) Antibacterial effects of a new dental acrylic resin containing silver nanoparticles. J Appl Polym Sci 110:1699-1703

6. Alt V, Bechert $T$, Steinrücke $P$, Wagener $M$, Seidel $P$, Dingeldein $E$, Doman $E$, Schnettler R (2004) An in vitro assessment of the antibacterial properties and cytotoxicity of nanoparticulate silver bone cement. Biomaterials 25:4383-4391

7. Jain P, Pradeep T (2005) Potential of silver nanoparticle-coated polyurethane foam as an antibacterial water filter. Biotechnol Bioeng 90:59-63

8. Sharma VK, Yngard RA, Lin Y (2009) Silver nanoparticles: green synthesis and their antimicrobial activities. Adv Colloid Interfac 145:83-96

9. de Mel A, Chaloupka K, Malam Y, Darbyshire A, Cousins B, Seifalian AM (2012) A silver nanocomposite biomaterial for blood-contacting implants. J Biomed Mater Res A Part A 100:2348-2357

10. Kokura S, Handa O, Takagi T, Ishikawa T, Naito Y, Yoshikawa, T (2010) AgNPs as a safe preservative for use in cosmetics. Nanotechnol 6:6570-574

11. Azeredo H (2009) Nanocomposites for food packaging applications. Res Int 42:1240-1253

12. Tsuji M, Gomi S, Maeda Y, Matsunaga M, Hikino S, Uto K, Tsuji T, Kawazumi H (2012) Rapid transformation from spherical nanoparticles, nanorods, cubes, or bipyramids to triangular prisms of silver with PVP, citrate, and $\mathrm{H}_{2} \mathrm{O}_{2}$. Langmuir 28:8845-8861 
13. Ghaffari-Moghaddam M, Hadi-Dabanlou R, Khajeh M, Rakhshanipour M, Shameli K (2014) Green synthesis of AgNPs using plant extracts. Korean J Chem Engineering 31:548-557

14. Banerjee P, Satapathy M, Mukhopahayay A, Das P (2014) Leaf extract mediated green synthesis of silver nanoparticles from widely available Indian plants: synthesis, characterization, antimicrobial property and toxicity analysis. Bioresources and Bioprocessing 1:3

15. Mohammadinejad R, Pourseyedi S, Baghizadeh A, Ranjbar S, Mansoori G (2013) Synthesis of silver nanoparticles using Silybum marianum seed extract. Int J Nanosci Nanotechnol 9:221-226

16. Swamy M.K, Sudipta K, Jayanta K, Balasubramanya S (2015) The green synthesis, characterization, and evaluation of the biological activities of silver nanoparticles synthesized from Leptadenia reticulata leaf extract Appl. Nanosci 5:1-9

17. Lei B, Zhang X, Zhu M, Tan W (2014) Effect of fluid shear stress on catalytic activity of biopalladium nanoparticles produced by Klebsiella Pneumoniae ECU-15 on $\mathrm{Cr}(\mathrm{VI})$ reduction reaction. Bioresources and Bioprocessing 1:28

18. Speth TF, Varma RS (2011) Microwave-assisted green synthesis of silver nanostructures. Accou of Chem Rese Acc of Cheml Resea 44:469-478

19. Song K, Lee S, Park T, Lee B (2009) Preparation of colloidal silver nanoparticles by chemical reduction method. Kore J of Che Eng 26:153-155

20. Li K, Zhang FS (2010) A novel approach for preparing silver nanoparticles under electron beam irradiation. J of Nanopa Resea 12:1423-1428

21. Harada M, Kawasaki C, Saijo K, Demizu M, Kimura Y (2010) Photochemical synthesis of silver particles using water-in-ionic liquid microemulsions in high-pressure $\mathrm{CO}_{2}$. J of Coll Interf Sci 343:537-545

22. Jensen MD, Malinsky CL, Haynes RPV (2000) Duyne, Nanosphere lithography: tunable localized surface plasmon resonance spectra of silver nanoparticles. J Phys Chem. 1041059

23. Philip D (2011) Mangifera indica leaf-assisted biosynthesis of well-dispersed AgNPs. Spectrochimica Acta 78:327-331

24. Bankar A, Joshi B, Kumar AR, Zinjarde S (2009) Banana peel extract mediated novel route for synthesis of AgNPs. Colloid Surf A Physicochem Eng 368:58-63

25. Dwivedi AD, Gopal K (2010) Biosynthesis of silver and gold nanoparticles using Chenopodium album leaf extract. Colloid Surf A Physicochem Eng Aspect 369:27-33

26. Velmurugan P, Shim J, Kamala-Kannan S, Lee KJ, Oh BT, Balachandar V (2011) Crystallization of silver through reduction process using Elaeis guineensis biosolid extract. Biotechnol Prog 27:273-279

27. Singh K, Panghal M, Kadyan S, Chaudhary U, Parkash YJ (2014) Antibacteria activity of synthesized silver nanoparticles from Tinospora cordifolia against multi drug resistant strains of pseudomonas aeruginosa isolated from burn patients. J Nanomed Nanotechnol 5:2

28. Dubey M, Bhadauria S, Kushwah BS (2009) Green synthesis of nanosilver particles from extract of Eucalyptus hybrida (safeda) leaf. Dig J Nanomater Bios 4(34):537-543

29. Kim SW, Jung JH, Lamsal K, Kim YS, Min JS, Lee YS (2012) Antifungal effects of silver nanoparticles (AgNPs) against various plant pathogenic fungi. Koren j of Microbiol 40:53-58

30. Mulvaney P (1996) Surface plasmon spectroscopy of nanosized metal particles. Longmuir 12:788-800

31. Khatami M, Pourseyedi S (2015) Phoenix dactylifera (date palm) pit aqueous extract mediated novel route for synthesis high stable AgNPs with high antifungal and antibacterial activity. IET Nanobiotechnol 9:1-7

32. Yilmaz M, Turkdemir H, Kilic MA, Bayram E, Cicek A, Mete A, Ulug B (2011) Biosynthesis of AgNPs using leaves of Stevia rebaudiana. Mater Chem Phys 130:1195-1202

33. Kaviya S, Santhanalakshmi J, Viswanathan B, Muthumary J, Srinivasan K (2011) Biosynthesis of silver nanoparticles using Citrus sinensis peel extract and its antibacterial activity. Spectrochimica Acta 79:594-598

\section{Submit your manuscript to a SpringerOpen ${ }^{\circ}$ journal and benefit from:}

- Convenient online submission

- Rigorous peer review

- Immediate publication on acceptance

- Open access: articles freely available online

- High visibility within the field

- Retaining the copyright to your article

Submit your next manuscript at $>$ springeropen.com 